\title{
The Existence and Uniqueness of the Solution of a Nonlinear Fredholm-Volterra Integral Equation with Modified Argument via Geraghty Contractions
}

\author{
Maria Dobriţoiu
}

check for

updates

Citation: Dobriţoiu, M. The Existence and Uniqueness of the Solution of a Nonlinear Fredholm-Volterra Integral Equation with Modified Argument via Geraghty Contractions. Mathematics 2021, 9, 29. https://dx.doi.org/ 10.3390/math9010029

Received: 13 November 2020 Accepted: 20 December 2020 Published: 24 December 2020

Publisher's Note: MDPI stays neutral with regard to jurisdictional claims in published maps and institutional affiliations.

Copyright: (C) 2020 by the author. Licensee MDPI, Basel, Switzerland. This article is an open access article distributed under the terms and conditions of the Creative Commons Attribution (CC BY) license (https: / / creativecommons.org/ licenses/by/4.0/).
Department of Mathematics and Computer Science, University of Petroşani, 332006 Petroşani, Romania; mariadobritoiu@yahoo.com or MariaDobritoiu@upet.ro

Abstract: Using some of the extended fixed point results for Geraghty contractions in $b$-metric spaces given by Faraji, Savić and Radenović and their idea to apply these results to nonlinear integral equations, in this paper we present some existence and uniqueness conditions for the solution of a nonlinear Fredholm-Volterra integral equation with a modified argument.

Keywords: $b$-metric space; Geraghty contraction; fixed point; integral equation; modified argument MSC: 45G10; 47H10

\section{Introduction}

As a generalization of the metric space, Bakhtin [1] introduced the notion of $b$-metric space and since then, several papers have been published on the fixed point theory in such spaces. Subsequently, many results in $b$-metric spaces have been obtained and published and some of them can be found in ([2-9]).

Let $\mathrm{X}$ be a nonempty set and $s \geq 1$ be a given real number.

Definition 1 ([3]). A function $d: X \times X \rightarrow[0,+\infty)$ is called a b-metric on $X$ if the following conditions hold:

(i) $\quad d(x, y)=0$ if and only if $x=y$, for all $x, y \in X$;

(ii) $d(x, y)=d(y, x)$, for all $x, y \in X$;

(iii) $d(x, y) \leq s[d(x, z)+d(z, y)]$, for all $x, y, z \in X$,

and the pair $(X, d)$ is called a $b$-metric space with coefficient $s \geq 1$.

Remark 1 ([4]).

1. If $s=1$, then the $b$-metric space is the usual metric space.

2. The notions of $b$-convergence, $b$-completeness and $b$-Cauchy sequence in a b-metric space can be found in [8].

In 1973, Geraghty [10] introduced a new class of contractions and investigated the existence and uniqueness of such mappings to generalize Banach's Contraction Principle. Let $S$ be the family of all functions $\alpha:[0, \infty) \rightarrow[0,1)$ that satisfy the following property:

$$
\lim _{n \rightarrow \infty} \alpha\left(t_{n}\right)=1 \Longrightarrow \lim _{n \rightarrow \infty} t_{n}=0
$$

and in [10], Geraghty presents the following theorem of existence and uniqueness.

Theorem 1 ([10]). Let $(X, d)$ be a complete metric space. Let $T: X \rightarrow X$ be a given mapping that satisfies the condition

$$
d(T(x), T(y)) \leq \alpha(d(x, y)) d(x, y), \text { for all } x, y \in X,
$$


where $\alpha \in S$. Then $T$ has a unique fixed point.

In 2011, Dukic et al. [2] reconsidered Theorem 1 in the framework of $b$-metric spaces.

Let $(X, d)$ be a $b$-metric space with coefficient $s \geq 1$ and $S$ denote the set of all functions $\alpha:[0, \infty) \rightarrow\left[0, \frac{1}{s}\right)$ that satisfy the following condition:

$$
\lim _{n \rightarrow \infty} \alpha\left(t_{n}\right)=\frac{1}{s} \Longrightarrow \lim _{n \rightarrow \infty} t_{n}=0 .
$$

We note that in paper [2], the authors used another set S, which they also denoted by $\mathrm{S}$. The obtained result is presented below.

Theorem 2 ([2]). Let $(X, d)$ be a b-complete b-metric space with coefficient $s \geq 1$ and a selfmapping $T: X \rightarrow X$. Suppose that there exists $\beta \in S$ such that the following condition is satisfied:

$$
d(T(x), T(y)) \leq \beta(d(x, y)) d(x, y), \text { for all } x, y \in X .
$$

Then Thas a unique fixed point in $X$.

Using these theorems, in 2019, Faraji et. al. [3] presented other fixed point results for Geraghty contraction in $b$-metric spaces and their applications to integral equations. We will detail these results in the next section.

The results of Geraghty in the context of various metric spaces have been extended by many researchers (see [2,3,6-9]).

The multitude of fixed point results in metric and $b$-metric spaces have many applications in the study of the solutions of certain integral equations, some of which are presented in the papers $[3,4,6,9,11-16]$.

In this paper, we will apply some of the extended fixed point results for Geraghty contractions in $b$-metric spaces, presented in ([3]), to a nonlinear Fredholm-Volterra integral equation with modified argument.

\section{Existing Results}

In 2019, Faraji et. al. [3] obtained and published two fixed point theorems for Geraghty contraction on $b$-metric spaces and their applications, which we present below.

Denote by $\mathbb{B}$ the set of all functions $\beta:[0, \infty) \rightarrow\left[0, \frac{1}{s}\right)$ that satisfy the condition $\lim \sup _{n \rightarrow \infty} \beta\left(t_{n}\right)=\frac{1}{s}$ implies that $t_{n} \rightarrow 0$ as $n \rightarrow \infty$. [8].

Theorem 3 ([3]). Let $(X, d)$ be a b-complete $b$-metric space with coefficient $s \geq 1$ and a selfmapping on $X, T: X \rightarrow X$, that satisfies the following condition:

$$
d(T(x), T(y)) \leq \beta(M(x, y)) M(x, y), x, y \in X,
$$

where

$$
M(x, y)=\max \left\{d(x, y), d(x, T(x)), d(y, T(y)), \frac{d(x, T(y))+d(y, T(x))}{2 s}\right\},
$$

and $\beta \in \mathbb{B}$. Then T has a unique fixed point in $X$.

Theorem 4 ([3]). Let $(X, d)$ be a b-complete b-metric space with coefficient $s \geq 1$ and two selfmappings on $X, T, S: X \rightarrow X$, that satisfy the following condition:

$$
s d(T(x), S(y)) \leq \beta(M(x, y)) M(x, y), x, y \in X,
$$

where $M(x, y)=\max \{d(x, y), d(x, T(x)), d(y, S(y))\}$ and $\beta \in \mathbb{B}$. If $T$ or $S$ are continuous, then $T$ and $S$ have a unique common fixed point in $X$. 
Remark 2. It is observed that if $T=S$, an interesting result is obtained that we present below in Corollary 1 ([3]).

Corollary 1 ([3]). Let $(X, d)$ be a b-complete b-metric space with coefficient $s \geq 1$ and a continuous self-mapping on $X, T: X \rightarrow X$, which satisfies the condition

$$
s d(T(x), T(y)) \leq \beta(M(x, y)) M(x, y), x, y \in X,
$$

where $M(x, y)=\max \{d(x, y), d(x, T(x)), d(y, T(y))\}$ and $\beta \in \mathbb{B}$. Then $T$ has a unique fixed point in $X$.

In addition, in [3], the authors present two applications of these theorems to a nonlinear integral equation (see Theorems 5 and 6 in [3]). For the convenience of the reader we shall present these two results below.

Let $(C[0, l], d)$ be a $b$-complete $b$-metric space with parameter $s=2$, where $C[0, l]$ is the set of all real continuous functions on $[0, l]$, and $d: C[0, l] \times C[0, l] \rightarrow[0, \infty)$ is a metric defined by the relation $d(x, y)=\max _{t \in[a, b]}|x(t)-y(t)|^{2}, x, y \in C[0, l]$.

First, the authors considered the following integral equation:

$$
u(t)=\int_{0}^{l} G(t, s) k(t, s, u(s)) d s,
$$

where $l>0, G \in C([0, l] \times[0, l])$ and $k \in C([0, l] \times[0, l] \times \mathbb{R})$, and they established the result of existence and uniqueness presented below.

Theorem 5 ([3]). Suppose that the following hypotheses hold:

(i) for all $t, s \in[0, l]$ and $u, v \in C[0, l]$, we have:

$$
|k(t, s, u(s))-k(t, s, v(s))| \leq \frac{\sqrt{e^{-M(u, v)} M(u, v)}}{2}
$$

(ii) for all $t, s \in[0, l]$, we have:

$$
\max _{t \in[0, l]} \int_{0}^{l} G(t, s)^{2} d s \leq \frac{1}{l} .
$$

Then, the integral equation above has a unique solution, $u \in C[0, l]$.

Secondly, the authors worked with the complete $b$-metric space with parameter $s=$ $2^{p-1},(C[a, b], d)$, where $C[a, b]$ is the set of all real continuous functions on $[a, b]$, and $d$ : $C[a, b] \times C[a, b] \rightarrow[0, \infty)$ is a metric defined by the relation $d(x, y)=\max _{t \in[a, b]} \mid x(t)-$ $\left.y(t)\right|^{p}, p>1, x, y \in C[a, b]$. To establish the conditions of a unique common solution existence, the following two integral equations were considered:

$$
\begin{aligned}
& u(t)=\int_{a}^{b} G(t, s) k_{1}(t, s, u(s)) d s, \\
& u(t)=\int_{a}^{b} G(t, s) k_{2}(t, s, u(s)) d s,
\end{aligned}
$$

where $G \in C([a, b] \times[a, b])$ and $k_{1}, k_{2} \in C([a, b] \times[a, b] \times \mathbb{R})$. The obtained result is presented below.

Theorem 6 ([3]). Suppose that 
(i) for all $t, s \in[a, b]$ and $u, v \in C[a, b]$, we have

$$
\left|k_{1}(t, s, u(s))-k_{2}(t, s, v(s))\right| \leq\left(\frac{\ln \left(1+|u(s)-v(s)|^{p}\right)}{2^{2 p-1}}\right)^{\frac{1}{p}}
$$

(ii) for all $t, s \in[a, b]$, we have

$$
\max _{t \in[a, b]} \int_{a}^{b} G(t, s)^{q} d s \leq \frac{1}{(b-a)^{\frac{q}{p}}}, \quad \frac{1}{p}+\frac{1}{q}=1 .
$$

Then, these integral equations have a unique common solution.

In 2006, in [15], using Banach's Contraction Principle and Schauder's Theorem, we obtained the results of existence and uniqueness of the solution of the following nonlinear Fredholm-Volterra integral equation with a modified argument:

$$
x(t)=F\left(t, \int_{a}^{b} K\left(t, s, x\left(g_{1}(s)\right)\right) d s, \int_{a}^{t} H\left(t, s, x\left(g_{2}(s)\right)\right) d s\right),
$$

where $F:[a, b] \times \mathbb{R}^{2} \rightarrow \mathbb{R}, K, H:[a, b] \times[a, b] \times \mathbb{R} \rightarrow \mathbb{R}, g_{1}, g_{2}:[a, b] \rightarrow[a, b]$ are given functions and $x:[a, b] \rightarrow \mathbb{R}$ is the unknown function.

In this paper we present an application of Theorems 3-5 and Corollary 1 to the nonlinear Fredholm-Volterra integral Equation (1). We obtain new conditions of existence and uniqueness for the solution of this integral equation. In addition, using these results and Theorem 6, we obtain a common fixed point result for two integral equations of this type. These results are fixed point theorems obtained by using the Geraghty contraction in a $b$-complete $b$-metric space.

\section{Main Results}

In this section, we establish the existence and uniqueness conditions for the solution of the nonlinear integral Equation (1), as an application of the fixed point theorems presented in the previous section.

Let $X=C[a, b]$ be the set of all real continuous functions on $[a, b]$ and the metric $d: X \times X \rightarrow[0, \infty)$, defined by the relation

$$
d(x, y)=\max _{t \in[a, b]}|x(t)-y(t)|^{2}, x, y \in X
$$

It is clear that $(X, d)$ is a $b$-complete $b$-metric space with coefficient $s=2$. Suppose that the following conditions hold:

$\left(a_{1}\right) \quad F \in C\left([a, b] \times \mathbb{R}^{2}\right)$;

$\left(a_{2}\right) \quad K, H \in C([a, b] \times[a, b] \times \mathbb{R})$;

(a) $g_{1}, g_{2} \in C([a, b],[a, b])$.

To obtain a theorem of existence and uniqueness of the solution of the FredholmVolterra nonlinear integral Equation (1) in the space $C[a, b]$, we will reduce the problem of determination of the solutions of this integral equation to a fixed point problem. For this purpose we consider the operator $A: C[a, b] \rightarrow C[a, b]$, defined by the relation

$$
A(x)(t):=F\left(t, \int_{a}^{b} K\left(t, s, x\left(g_{1}(s)\right)\right) d s, \int_{a}^{t} H\left(t, s, x\left(g_{2}(s)\right)\right) d s\right), t \in[a, b] .
$$

The set of the solutions of the integral Equation (1) in the space $C[a, b]$ coincides with the fixed points set of the operator A, defined by the relation in Equation (2). 
We now apply Theorem 3 from the previous section, and for this, we use the metric $d$ defined above. Therefore, we have

$$
\begin{gathered}
d(A(x), A(y))=\max _{t \in[a, b]}|A(x)(t)-A(y)(t)|^{2}= \\
=\max _{t \in[a, b]} \mid F\left(t, \int_{a}^{b} K\left(t, s, x\left(g_{1}(s)\right)\right) d s, \int_{a}^{t} H\left(t, s, x\left(g_{2}(s)\right)\right) d s\right)- \\
-\left.F\left(t, \int_{a}^{b} K\left(t, s, y\left(g_{1}(s)\right)\right) d s, \int_{a}^{t} H\left(t, s, y\left(g_{2}(s)\right)\right) d s\right)\right|^{2},
\end{gathered}
$$

for all $x, y \in C[a, b]$.

Next, suppose that

$$
\left|F\left(t, u_{1}(t), u_{2}(t)\right)-F\left(t, v_{1}(t), v_{2}(t)\right)\right| \leq\left|u_{1}(t)-v_{1}(t)\right|+\left|u_{2}(t)-v_{2}(t)\right|,
$$

for all $t \in[a, b], u_{1}, u_{2}, v_{1}, v_{2} \in C[a, b]$. Using Equation (4), the relation in Equation (3) becomes

$$
\begin{aligned}
d(A(x), A(y)) \leq \max _{t \in[a, b]}\left\{\left|\int_{a}^{b}\left[K\left(t, s, x\left(g_{1}(s)\right)\right)-K\left(t, s, y\left(g_{1}(s)\right)\right)\right] d s\right|+\right. \\
\left.\quad+\left|\int_{a}^{t}\left[H\left(t, s, x\left(g_{2}(s)\right)\right)-H\left(t, s, y\left(g_{2}(s)\right)\right)\right] d s\right|\right\}^{2} \\
\leq \max _{t \in[a, b]}\left|\int_{a}^{b}\left[K\left(t, s, x\left(g_{1}(s)\right)\right)-K\left(t, s, y\left(g_{1}(s)\right)\right)\right] d s\right|^{2}+ \\
+2 \max _{t \in[a, b]}\left|\int_{a}^{b}\left[K\left(t, s, x\left(g_{1}(s)\right)\right)-K\left(t, s, y\left(g_{1}(s)\right)\right)\right] d s\right| \\
\quad \cdot\left|\int_{a}^{t}\left[H\left(t, s, x\left(g_{2}(s)\right)\right)-H\left(t, s, y\left(g_{2}(s)\right)\right)\right] d s\right|+ \\
+\max _{t \in[a, b]}\left|\int_{a}^{t}\left[H\left(t, s, x\left(g_{2}(s)\right)\right)-H\left(t, s, y\left(g_{2}(s)\right)\right)\right] d s\right|^{2} \\
\leq \max _{t \in[a, b]}\left|\int_{a}^{b}\right| K\left(t, s, x\left(g_{1}(s)\right)\right)-K\left(t, s, y\left(g_{1}(s)\right)\right)|d s|^{2}+ \\
+2 \max _{t \in[a, b]}\left\{\int_{a}^{b}\left|K\left(t, s, x\left(g_{1}(s)\right)\right)-K\left(t, s, y\left(g_{1}(s)\right)\right)\right| d s .\right. \\
\left.\quad \cdot \int_{a}^{t}\left|H\left(t, s, x\left(g_{2}(s)\right)\right)-H\left(t, s, y\left(g_{2}(s)\right)\right)\right| d s\right\}+ \\
+\max _{t \in[a, b]}\left|\int_{a}^{t}\right| H\left(t, s, x\left(g_{2}(s)\right)\right)-H\left(t, s, y\left(g_{2}(s)\right)\right)|d s|^{2} . \\
\\
+
\end{aligned}
$$

Now, using Theorem 5 presented in Section 2 (see Theorem 5 in [3]), suppose that for all $t, s \in[a, b], u, v \in C[a, b]$, the following two conditions are fulfilled:

$$
\begin{aligned}
& |K(t, s, u(s))-K(t, s, v(s))| \leq \frac{\sqrt{e^{-M(u, v)} M(u, v)}}{8(b-a)} \\
& |H(t, s, u(s))-H(t, s, v(s))| \leq \frac{\sqrt{e^{-M(u, v)} M(u, v)}}{8(b-a)}
\end{aligned}
$$


If we use (6) and (7), then for all $s \in[a, b]$, the relation in Equation (5) becomes

$$
d(A(x), A(y)) \leq 4(b-a)^{2} \frac{e^{-M(x, y)} M(x, y)}{8(b-a)^{2}}
$$

and we have obtained

$$
d(A(x), A(y)) \leq \frac{e^{-M(x, y)}}{2} M(x, y) .
$$

Now we consider the function $\beta(t)=\frac{e^{-t}}{2}, t>0$, and the relation in Equation (9) becomes

$$
d(A(x), A(y)) \leq \beta(M(x, y)) M(x, y)
$$

and thus, the conditions of Theorem 3 are satisfied.

Therefore, applying Theorem 3, it results that the operator A has a unique fixed point and thus, we obtain a theorem of the existence and uniqueness of the solution of the integral Equation (1), which we present below.

Theorem 7. Suppose that the conditions $\left(a_{1}\right)-\left(a_{3}\right)$ hold. In addition, we assume that

(i) $\left|F\left(t, u_{1}, u_{2}\right)-F\left(t, v_{1}, v_{2}\right)\right| \leq\left|u_{1}-v_{1}\right|+\left|u_{2}-v_{2}\right|$, for all $t \in[a, b], u_{1}, u_{2}, v_{1}, v_{2} \in \mathbb{R}$;

(ii) $|K(t, s, u(s))-K(t, s, v(s))| \leq \frac{\sqrt{e^{-M(u, v)} M(u, v)}}{8(b-a)}$, for all $t, s \in[a, b], u, v \in C[a, b]$;

(iii) $|H(t, s, u(s))-H(t, s, v(s))| \leq \frac{\sqrt{e^{-M(u, v)} M(u, v)}}{8(b-a)}$, for all $t, s \in[a, b], u, v \in C[a, b]$.

Then the integral Equation (1) has a unique solution $x^{*} \in C[a, b]$.

In what follows, we consider the space $X=C[a, b]$ the set of all real continuous functions on $[a, b]$, endowed with the $b$-metric $d: X \times X \rightarrow[0, \infty)$, defined by the relation

$$
d(x, y)=\max _{t \in[a, b]}|x(t)-y(t)|^{p}, p>1, x, y \in X
$$

It is clear that $(X, d)$ is a complete $b$-metric space with coefficient $s=2^{p-1}$.

Next, we consider the following two nonlinear Fredholm-Volterra integral equations:

$$
x(t)=F\left(t, \int_{a}^{b} K_{1}\left(t, s, x\left(g_{1}(s)\right)\right) d s, \int_{a}^{t} H_{1}\left(t, s, x\left(g_{2}(s)\right)\right) d s\right),
$$

and

$$
x(t)=F\left(t, \int_{a}^{b} K_{2}\left(t, s, x\left(g_{1}(s)\right)\right) d s, \int_{a}^{t} H_{2}\left(t, s, x\left(g_{2}(s)\right)\right) d s\right),
$$

where $F:[a, b] \times \mathbb{R}^{2} \rightarrow \mathbb{R}, K_{1}, H_{1}, K_{2}, H_{2}:[a, b] \times[a, b] \times \mathbb{R} \rightarrow \mathbb{R}$ and $g_{1}, g_{2}:[a, b] \rightarrow[a, b]$ are given functions.

Suppose that the following conditions hold:

(b 1$) \quad F \in C\left([a, b] \times \mathbb{R}^{2}\right)$;

$\left(b_{2}\right) \quad K_{1}, H_{1} \in C([a, b] \times[a, b] \times \mathbb{R})$;

(b) $K_{2}, H_{2} \in C([a, b] \times[a, b] \times \mathbb{R})$;

(bu) $g_{1}, g_{2} \in C([a, b],[a, b])$.

To obtain a result of a common solution of the integral equations in Equations (10) and (11), we will again use a fixed point problem. For this reason, we consider two operators, $A, B: C[a, b] \rightarrow C[a, b]$, defined by the relations

$$
A(x)(t):=F\left(t, \int_{a}^{b} K_{1}\left(t, s, x\left(g_{1}(s)\right)\right) d s, \int_{a}^{t} H_{1}\left(t, s, x\left(g_{2}(s)\right)\right) d s\right), t \in[a, b]
$$


and

$$
B(x)(t):=F\left(t, \int_{a}^{b} K_{2}\left(t, s, x\left(g_{1}(s)\right)\right) d s, \int_{a}^{t} H_{2}\left(t, s, x\left(g_{2}(s)\right)\right) d s\right), t \in[a, b] .
$$

We have

$$
\begin{gathered}
d(A(x), B(y))=\max _{t \in[a, b]}|A(x)(t)-B(y)(t)|^{p}= \\
=\max _{t \in[a, b]} \mid F\left(t, \int_{a}^{b} K_{1}\left(t, s, x\left(g_{1}(s)\right)\right) d s, \int_{a}^{t} H_{1}\left(t, s, x\left(g_{2}(s)\right)\right) d s\right)- \\
-\left.F\left(t, \int_{a}^{b} K_{2}\left(t, s, y\left(g_{1}(s)\right)\right) d s, \int_{a}^{t} H_{2}\left(t, s, y\left(g_{2}(s)\right)\right) d s\right)\right|^{p} .
\end{gathered}
$$

Suppose that the condition in Equation (4) is satisfied. In addition, suppose that

$$
\left|u_{2}(t)-v_{2}(t)\right| \leq\left|u_{1}(t)-v_{1}(t)\right|, \quad \text { for all } t \in[a, b]
$$

and then the condition in Equation (4) becomes

$$
\left|F\left(t, u_{1}(t), u_{2}(t)\right)-F\left(t, v_{1}(t), v_{2}(t)\right)\right| \leq 2\left|u_{1}(t)-v_{1}(t)\right|,
$$

for all $t \in[a, b], u_{1}, u_{2}, v_{1}, v_{2} \in C[a, b]$.

Now, using Theorem 6, presented in Section 2 (see Theorem 6 in [3]), suppose that

$$
\left|K_{1}(t, s, u(s))-K_{2}(t, s, v(s))\right| \leq\left(\frac{\ln \left(1+|u(s)-v(s)|^{p}\right)}{2^{2 p-1}(b-a)}\right)^{\frac{1}{p}},
$$

for all $t, s \in[a, b], u, v \in C[a, b]$.

In what follows, we use the conditions in Equations (16) and (17), and the relation in Equation (14) becomes

$$
\begin{gathered}
d(A(x), B(y)) \leq 2 \max _{t \in[a, b]}\left|\int_{a}^{b}\left[K_{1}\left(t, s, x\left(g_{1}(s)\right)\right)-K_{2}\left(t, s, y\left(g_{1}(s)\right)\right)\right] d s\right|^{p} \\
\leq 2 \max _{t \in[a, b]}\left|\int_{a}^{b}\right| K_{1}\left(t, s, x\left(g_{1}(s)\right)\right)-K_{2}\left(t, s, y\left(g_{1}(s)\right)\right)|d s|^{p} \\
\leq 2\left(\int_{a}^{b}\left(\frac{\ln (1+d(x, y))}{2^{2 p-1}(b-a)}\right)^{\frac{1}{p}} d s\right)^{p} \leq \frac{\ln (1+M(x, y))}{2^{2(p-1)}}
\end{gathered}
$$

Finally, we obtain the following result:

$$
2^{p-1} d(A(x), B(y)) \leq \frac{M(x, y)}{2^{p-1}} \leq \frac{1}{2^{p-1}} M(x, y) .
$$

Now we consider the function $\beta(t)=\frac{1}{2^{p-1}}, p>1, t>0$, and the relation in Equation (19) becomes

$$
2^{p-1} d(A(x), B(y)) \leq \beta(M(x, y)) M(x, y)
$$

and thus, the conditions of Theorem 4 are satisfied.

Therefore, applying Theorem 4 , it results that the operators $A$ and $B$ have a unique common fixed point, and thus we obtain a theorem that we state below.

Theorem 8. Suppose that the conditions $\left(b_{1}\right)-\left(b_{4}\right)$ hold. Moreover, assume that (i) $\left|F\left(t, u_{1}, u_{2}\right)-F\left(t, v_{1}, v_{2}\right)\right| \leq 2\left|u_{1}-v_{1}\right|$, for all $t \in[a, b], u_{1}, u_{2}, v_{1}, v_{2} \in \mathbb{R}$; 
(ii) $\begin{aligned} & \left|K_{1}(t, s, u(s))-K_{2}(t, s, v(s))\right| \leq\left(\frac{\ln \left(1+|u(s)-v(s)|^{p}\right)}{2^{2 p-1}(b-a)}\right)^{\frac{1}{p}}, p>1, \text { for all } t, s \in[a, b], u, v \in \\ & C[a, b] .\end{aligned}$

Then the Fredholm-Volterra nonlinear integral Equations (10) and (11) have a unique common solution in $C[a, b]$.

Finally, we present two examples, which are applications of Theorem 7 and Theorem 8 , respectively.

Example 1. Consider the following nonlinear Fredholm integral equation with modified argument:

$$
x(t)=\int_{0}^{1} \frac{e^{-x(s / 2)} \sin (x(s / 2))}{t+s+2} d s, \quad t \in[0,1],
$$

where $K:[0,1] \times[0,1] \times \mathbb{R} \rightarrow \mathbb{R}, K(t, s, u)=\frac{e^{-u} \sin (u)}{t+s+2}$ and $g:[0,1] \rightarrow[0,1], g(s)=\frac{s}{2}$, are continuous functions. For all $t, s \in[0,1], x, y \in C[0,1]$, the following condition is satisfied:

$$
\begin{gathered}
|K(t, s, x(s / 2))-K(t, s, y(s / 2))|= \\
=\left|\frac{e^{-x(s / 2)} \sin (x(s / 2))-e^{-y(s / 2)} \sin (y(s / 2))}{t+s+2}\right| \\
\leq \frac{\sqrt{e^{-M(x, y)} M(x, y)}}{2}
\end{gathered}
$$

and applying Theorem 7 , it results that the integral Equation (20) has a unique solution $x^{*} \in C[0,1]$.

Example 2. Consider the following two nonlinear Fredholm integral equations with modified argument:

$$
\begin{gathered}
x(t)=\int_{0}^{1} \frac{t+s+1}{24} x(s / 2) d s, \quad t \in[0,1], \\
x(t)=\int_{0}^{1} \frac{x(s / 2)}{2 t+s+5} d s, \quad t \in[0,1],
\end{gathered}
$$

where $K_{1}, K_{2}:[0,1] \times[0,1] \times \mathbb{R} \rightarrow \mathbb{R}, K_{1}(t, s, u)=\frac{t+s+1}{24} u, K_{2}(t, s, u)=\frac{u}{2 t+s+5}$, and $g$ : $[0,1] \rightarrow[0,1], g(s)=\frac{s}{2}$, are continuous functions. For all $t, s \in[0,1], x, y \in C[0,1]$, the following condition is satisfied:

$$
\begin{gathered}
\left|K_{1}(t, s, x(s / 2))-K_{2}(t, s, y(s / 2))\right|= \\
=\left|\frac{t+s+1}{24} x(s / 2)-\frac{1}{2 t+s+5} y(s / 2)\right| \\
\leq \frac{1}{8}|x(s / 2)-y(s / 2)| \leq \frac{|x(s / 2)-y(s / 2)|^{2}}{8} \\
\leq \sqrt{\frac{\ln \left(1+|x(s / 2)-y(s / 2)|^{2}\right)}{8}} .
\end{gathered}
$$

Now, by applying Theorem $8(p=2)$, it results that the integral Equations (21) and (22) have a unique common solution in $C[0,1]$.

\section{Conclusions}

With the introduction of the notion of $b$-metric space as a generalization of the notion of metric space, for many of the fixed point results obtained in metric spaces, we studied new conditions that ensure the existence and uniqueness of the fixed point in $b$-metric spaces. At the same time, we investigated several types of contractions and generalized 
contractions. The integral Equation (1) was studied in the paper [15], and conditions for the existence and uniqueness of the solution were established:

- $\quad$ in the space $C[a, b]$, using the contractions, by applying Banach's Contraction Principle, and

- $\quad$ in the space $C\left([a, b], \mathbb{R}^{m}\right)$, using the generalized contractions, by applying Perov's Theorem.

In this paper are presented two fixed point results in $b$-metric spaces, for the studied integral equation, obtained using the Geraghty contractions.

The results presented in this paper can be applied to the nonlinear Fredholm-Volterra integral equations with modified argument, and as examples we mention the following.

(i) Fredholm integral equation:

$$
x(t)=\int_{a}^{b} K(t, s, x(s)) d s+f(t), \quad t \in[a, b] ;
$$

(ii) Fredholm integral equation with modified argument:

$$
x(t)=\int_{a}^{b} K(t, s, x(g(s))) d s+f(t), \quad t \in[a, b]
$$

(iii) Volterra integral equation:

$$
x(t)=\int_{a}^{t} K(t, s, x(s)) d s+f(t), \quad t \in[a, b] ;
$$

(iv) Volterra integral equation with modified argument:

$$
x(t)=\int_{a}^{t} K(t, s, x(g(s))) d s+f(t), \quad t \in[a, b] ;
$$

(v) Fredholm-Volterra integral equation with modified argument:

$$
x(t)=\int_{a}^{b} K\left(t, s, x\left(g_{1}(s)\right)\right) d s+\int_{a}^{t} H\left(t, s, x\left(g_{2}(s)\right)\right) d s+f(t), \quad t \in[a, b] ;
$$

(vi) Fredholm-Volterra implicit integral equation with modified argument:

$$
x(t)=F\left(t, x(a), \int_{a}^{b} K\left(t, s, x\left(g_{1}(s)\right)\right) d s, \int_{a}^{t} H\left(t, s, x\left(g_{2}(s)\right)\right) d s\right), \quad t \in[a, b] .
$$

Funding: This research received no external funding.

Data Availability Statement: Not applicable.

Acknowledgments: The author is grateful to the reviewers for their valuable suggestions on this paper.

Conflicts of Interest: The author declares no conflict of interest.

\section{References}

1. Bakhtin, I.A. The contraction mapping principle in almost metric space. In Functional Analysis; Gos. Ped. Inst.: Ulýanovsk, Russia, 1989; pp. 26-37. (In Russian)

2. Dukic, D.; Kadelburg, Z.; Radenović, S. Fixed points of Geraghty-type mappings in various generalized metric spaces. Abstr. Appl. Anal. 2011, 561245.

3. Faraji, H.; Savić, D.; Radenović, S. Fixed Point Theorems for Geraghty Contraction Mappings in $b$-Metric Spaces and Applications. Axioms 2019, 8, 34. [CrossRef]

4. Dobriţoiu, M. An application of the admissibility types in b-metric spaces. Transylv. J. Math. Mech. 2020, 12, 11-16. 
5. Ilea, V; Otrocol, D. Existence and Uniqueness of the Solution for an Integral Equation with Supremum, via w-Distances. Symmetry 2020, 12, 1554. [CrossRef]

6. Radenović, S.; Došenović, T.; Ozturk, V.; Dolićanin, Ć. A note on the paper: "Nonlinear integral equations with new admissibility types in b-metric spaces". J. Fixed Point Theory Appl. 2017, 19, 2287-2295. [CrossRef]

7. Huang, H.; Paunović, L.; Radenović, S. On some fixed point results for rational Geraghty contractive mappings in ordered b-metric spaces. J. Nonlinear Sci. Appl. 2015, 8, 800-807. [CrossRef]

8. Shahkoohi, R.J.; Razani, A. Some fixed point theorems for rational Geraghty contractive mappings in ordered $b$-metric spaces. J. Inequal. Appl. 2014, 2014:373. [CrossRef]

9. Sintunavarat, W. Nonlinear integral equations with new admissibility types in b-metric spaces. J. Fixed Point Theory Appl. 2016 18, 397-416. [CrossRef]

10. Geraghty, M.A. On contractive mappings. Proc. Am. Math. Soc. 1973, 40, 604-608. [CrossRef]

11. Dobriţoiu, M. Ecuaţii integrale cu argument modificat; Presa Universitară Clujeană Publishing House: Cluj-Napoca, Romania, 2009. (In Romanian)

12. Rus, I.A. Title. In Principii şi Aplicaţii ale Teoriei Punctului Fix; Dacia Publishing House: Cluj-Napoca, Romania, 1979. (In Romanian)

13. Dobriţoiu, M. A class of nonlinear integral equations. Transylv. J. Math. Mech. 2012, 4, 2, 117-123.

14. Dobriţoiu, M. Some Integral Equations with Modified Argument; WSEAS Press. 2016. Available online: www.wseas.org (accessed on 23 December 2020) .

15. Dobriţoiu, M. A Fredholm-Volterra integral equation with modified argument. Ann. Oradea Univ. Math. Fasc. 2006, XIII, 133-138.

16. András, S. Ecuaţii integrale Fredholm-Volterra; Didactică şi Pedagogică Publishing House: Bucureşti, Romania, 2005. (In Romanian) 